\title{
Comparison of relationships among French adult siblings with or without schizophrenia using the ASRQ-S: mediating effect on emotional distress
}

\author{
Léa Plessis $^{1 *}$, Hélène Wilquin ${ }^{1}$, Jean-Baptiste Pavani ${ }^{2}$ and Evelyne Bouteyre ${ }^{1}$
}

\begin{abstract}
Background: Good sibling relationships in adulthood are known to be a protective factor for mental health. The present study examined and compared the relationships of siblings with either a healthy brother or sister or one experiencing schizophrenia.

Methods: In the first phase, we ran a statistical comparison of the two sibling groups on the quality of their sibling relationships (warmth, conflict, and rivalry), emotional distress, and self-esteem. In the second phase, we looked at whether the quality of the sibling relationship modifies the impact of having a brother or sister with schizophrenia on emotional distress and self-esteem.

Results: Results showed that sibling relationships in schizophrenia are less warm and are characterized by heightened rivalry and conflict. In addition, analysis revealed a mediating effect of sibling relationship on the emotional distress of siblings with a brother/sister diagnosed with schizophrenia.

Conclusion: More needs to be done to enhance the mental health of adults who have a brother or sister with schizophrenia, notably via their sibling relationships.
\end{abstract}

Keywords: Sibling relationships, Schizophrenia, Matched samples, Emotional distress

\section{Background}

Schizophrenia (SZ) affects almost $1 \%$ of the population and has severe consequences for both the patient and the patient's family.

Published research on the adult siblings of individuals with SZ has so far been restricted to the impact of a first episode of psychosis (FEP) on siblings in their early 20s [1-4], their adaptation strategies [5-8], and the extent to which they fulfil the role of informal caregiver [9-14]. To our knowledge, healthy adults' perceptions of their relationship with a brother or sister experiencing SZ

\footnotetext{
* Correspondence: lea.plessis@univ-amu.fr

${ }^{1}$ LPCPP, Aix Marseille University, Aix-en-Provence, France

Full list of author information is available at the end of the article
}

have never been investigated beyond this first episode. We therefore carried out a novel comparison between the adult siblings of individuals with SZ and matched sets of siblings drawn from the general population on their experience of sibling relationships.

\section{Sibling relationships}

A subsystem of the family system, the sibling relationship is classically studied according to three dimensions: warmth, conflict, and rivalry $[15,16]$. Warmth can be defined as closeness and support within the relationship, while conflict refers to disagreements and quarrels within

C C The Author(s). 2020 Open Access This article is licensed under a Creative Commons Attribution 4.0 International License, which permits use, sharing, adaptation, distribution and reproduction in any medium or format, as long as you give appropriate credit to the original author(s) and the source, provide a link to the Creative Commons licence, and indicate if changes were made. The images or other third party material in this article are included in the article's Creative Commons licence, unless indicated otherwise in a credit line to the material. If material is not included in the article's Creative Commons licence and your intended use is not permitted by statutory regulation or exceeds the permitted use, you will need to obtain permission directly from the copyright holder. To view a copy of this licence, visit http://creativecommons.org/licenses/by/4.0/. The Creative Commons Public Domain Dedication waiver (http://creativecommons.org/publicdomain/zero/1.0/) applies to the data made available in this article, unless otherwise stated in a credit line to the data. 
that relationship, and rivalry corresponds to competition for parental affection and attention.

Good sibling relationships can be highly beneficial in terms of cognitive $[17,18]$, emotional $[19,20]$ and social development $[21,22]$. High on warmth and low on both conflict and rivalry [23], they are a prime protective factor for mental health [24], linked to greater self-confidence, better social skills, and general wellbeing $[23,25,26]$. They can also shield individuals from loneliness $[15,27,28]$ and keep depression and anxiety at bay $[15,29]$.

When individuals reach adulthood, life events such as finishing their formal education, entering the world of work, meeting new people, marrying, and starting a family often lead them to pursue fresh aspirations beyond the family circle [30, 31]. Unsurprisingly, most studies show that all three dimensions of sibling relationships are expressed less intensely in adulthood [32-35], although warmth prevails over both conflict and rivalry [21, 33, 36, 37]. Research on sibling relationships in adulthood is nevertheless particularly relevant, as these are the longest relationships that individuals have in their lifetime, outlasting those between parents and children or between spouses [21, 38, 39].

\section{Sibling relationships in adulthood and disability}

When individuals experience disability, they continue to receive support from their siblings in adulthood, although it may take several different forms (e.g., emotional or financial). Healthy individuals who assist and keep in regular contact with a brother or sister who has a disability report more positive feelings about their general wellbeing and their sibling relationships [40, 41].

Depending on the disability, some symptoms may nonetheless adversely affect relations with an ill sibling. For example, the siblings of individuals with autism report poorer relationships than the siblings of individuals with Down syndrome [42]. According to Travis and Sigman [43], this can probably be attributed to the particular nature of autism symptoms, which are characterized by a social deficit and limited interpersonal relations (impaired communication, social cognition, emotions and social relations).

Intellectual disability and developmental disorders are chronic in nature, whereas mental disorders bring with them the risk of relapse and variable symptoms, and may have more episodic manifestations. SZ usually manifests itself for the first time between the ages of 15 and 25 years, whereas autism is generally diagnosed around the age of 3 years [44]. Adaptation should not, however, be equated with acceptance, let alone understanding, of the illness, which can require a considerable length of time $[45,46]$.

\section{Sibling relationships in SZ}

When an individual is diagnosed with a mental disorder such as $\mathrm{SZ}$, it can come as a huge emotional shock to his or her healthy siblings, who typically experience a mixture of stress, denial, despair, fear, guilt and impotence $[3,4]$. The severity of the symptoms (e.g., delusions, hallucinations, behavioral problems, anhedonia, cognitive disorders and social withdrawal), combined with the chronic nature of the illness, places a heavy daily burden on all family members [47]. Moreover, as SZ often appears during adolescence or early adulthood, the ill person's siblings are generally still living at home. In this context, Bowman et al. [1] and Sin et al. [3, 4] studied the impact of an FEP on sibling relationships, but without a control group (e.g. siblings without a brother/sister with SZ). More specifically, Bowman et al. used the Adult Sibling Relationship Questionnaire (ASRQ) to examine how healthy individuals $(N=157$; $M_{\text {age }}=21.7$ years $)$ with a brother or sister who had experienced an FEP within the previous 18 months perceived their sibling relationships [1]. Results suggested that a history of violent behavior by the ill brother or sister was predictive of poorer sibling relations (less warmth, more conflict, and more rivalry).

\section{The present study}

The present study had two objectives. The first was to compare adult siblings with or without a brother or sister experiencing SZ on the quality of their sibling relationships, emotional distress, and self-esteem. Based on the literature, we expected the siblings of individuals with SZ to report less warmth, more conflict, and more rivalry than siblings drawn from the general population. The second objective was to clarify how the quality of the sibling relationship modifies the impact of having a brother or sister with SZ on emotional distress and self-esteem. We postulated that the quality of the sibling relationship has a mediating effect on both the emotional distress and self-esteem of siblings with a brother or sister diagnosed with SZ.

\section{Methods \\ Participants \\ Two initial samples}

We recruited two initial samples of French volunteers: a large sample of 1444 siblings $\left(76.5 \%\right.$ female; $M_{\text {age }}=$ 25.91 years, $S D=8.31$ ) drawn from the general population between September and November 2017; and a smaller sample of 201 siblings $\left(77.1 \%\right.$ female; $M_{\text {age }}=$ 37.9 years, $S D=12.08$ ) with a brother or sister with $\mathrm{SZ}$ between November 2017 and February 2018. All participants $(N=1645)$ completed an online questionnaire. The inclusion criteria for all participants were 1) aged at least 18 years, and 2) at least one sibling aged 18 years or over. For participants in the SZ sample, there was a third criterion: a sibling with SZ. Participants in this group reported having a sibling who had been diagnosed with SZ by a healthcare professional. 


\section{Sample matching procedure}

Each participant in the SZ sibling sample was matched with a participant in the general population sample on four criteria: age (within 5 years), sex, sex of target sibling, and birth order (younger or older than target sibling).

\section{Two matched groups}

With these four criteria, we were able to match 187 participants in the SZ sibling sample with 187 siblings from the general population. We therefore ended up with two matched groups, each with 187 participants $(N=374)$. In each group, the mean age was 35.9 years $(S D=10.7)$, $46.5 \%$ of participants were younger than the target sibling, $49.7 \%$ were older, and $3.7 \%$ were twins. In both samples, $77.5 \%$ of the participants were women, most of whom responded about their relationship with a brother (80.7\%). Fourteen participants in the original sample of 201 individuals with a sibling diagnosed with SZ could not be paired, mostly because of their age: nine of them were aged over 64 years, whereas the oldest participant in the general population sample was 64 years. The remaining five were twins for whom we were unable to find a matching twin of the same sex in the general sample $(N=1444)$.

\section{Procedures}

Janghorban, Roudsari, and Taghipour recommended recruiting participants via social media, instead of relying solely on psychiatric institutions or charitable bodies, in order to reach a broader population [48]. Participants were therefore recruited via social media and through the Union Nationale de Familles ou Amis de Personnes Malades et/ou Handicapées Psychiques ${ }^{1}$ (UNAFAM), a French charity that offers support to the families of persons with chronic mental disorders.

An electronic link to an online form was sent by social media group administrators, organization websites and charity newsletters to potential participants. After reading an information letter, participants had to validate their consent online. They could then gain access to the questionnaire, a self-administered online questionnaire that took approximately $40 \mathrm{~min}$ to complete.

\section{Ethical considerations}

The research protocol was approved by Lille University's ethics committee for human-based research (2018-276S61), and complied with the principles of the Declaration of Helsinki [49].

\footnotetext{
${ }^{1}$ National Union of Families or Friends of Persons with Mental Disorders and/or Disabilities.
}

\section{Measures \\ Sociodemographic data}

We collected participants' sociodemographic data and information about their family structure (see Table 1).

\section{Adult sibling relationship questionnaire-short form (ASRQ-S)}

The ASRQ-S is a self-report questionnaire assessing the qualitative features of sibling relationships in young adulthood and beyond. Participants were asked to report on a single sibling relationship. The original long-form version of the ASRQ (81 items) was developed by Stocker et al. [16] as an age-appropriate extension of the Sibling Relationship Questionnaire [50].

The short form of the ASRQ (ASRQ-S), developed by Lanthier, Stocker, and Furman but not yet validated or published, includes 47 of the 81 items in the full ASRQ [16] (cf. Supplementary Material). These 47 items are divided into eight subscales corresponding to the three above-mentioned factors: Knowledge, Intimacy, and Emotional Support (Warmth); Antagonism, Dominance, and Quarreling (Conflict); and Maternal Rivalry and Paternal Rivalry (Rivalry).

The ASRQ-S was translated into French using Vallerand's back-translation procedure, after obtaining the consent of the original authors [51]. A native English bilingual translated the English version of the ARSQ-S into French, and a second bilingual translated this French version back into English. When compared, the two English versions were initially found to have substantial incongruities. The French version was therefore self-administered by 10 siblings to identify potential problems or ambiguities arising from the translation. Their responses were used to produce the final French version of the ARSQ-S.

Three of the items (Items 10, 11 and 27) making up the dominance subscale were deleted from the French version because the component coefficients were not conclusive ( $>.30)$. After deleting these items, the French version of the ASRQ-S contained 44 items shared between three main factors, which themselves were divided into eight subscales. The French version of the ASRQ-S shows good internal consistency (minimum $\alpha=0.65$, maximum $\alpha=0.96$ ).

\section{Indicator of emotional distress}

We created an emotional distress indicator, using the French version of the Hospital Anxiety and Depression (HAD) scale translated and validated by Lepine, Godchau, and Brun [52]. This scale has two dimensions: depressive symptomatology and anxious symptomatology. Each dimension includes seven items rated on a 4-point Likert-like scale ranging from Never to Most of the time. The psychometric qualities of the HAD scale have good internal consistency $(\alpha=.81-.90)$. 
Table 1 Participants' sociodemographic and sibling-related characteristics

\begin{tabular}{|c|c|c|c|c|c|}
\hline Variables & $\begin{array}{l}\text { Modality (for categorical } \\
\text { variables) }\end{array}$ & $\begin{array}{l}\text { Total sample } \\
(N=374)\end{array}$ & $\begin{array}{l}\text { General population } \\
\text { group }(n=187)\end{array}$ & $\begin{array}{l}\text { Clinical siblings } \\
(n=187)\end{array}$ & $\begin{array}{l}t \text { or }_{\mathrm{chi}^{2}} \text { values for } \\
\text { unmatched variables }\end{array}$ \\
\hline Sex (\%) & Female & $288(77.00)$ & $144(77.00)$ & $144(77.00)$ & \\
\hline Mean age in years $(S D)$ & & $35.96(10.75)$ & $35.93(10.76)$ & $36(10.77)$ & -0.07 \\
\hline Professional activity (\%) & None & $90(24.06)$ & $55(29.41)$ & $35(18.72)$ & $5.28^{*}$ \\
\hline $\begin{array}{l}\text { Sex of target brother or sister } \\
(\%)\end{array}$ & Female & $74(19.79)$ & $37(19.79)$ & 37 (19.79) & \\
\hline $\begin{array}{l}\text { Mean age difference between } \\
\text { the two siblings (SD) }\end{array}$ & & $-0.26(5.24)$ & $-0.67(4.29)$ & $0.14(6.02)$ & -1.49 \\
\hline \multirow[t]{3}{*}{ Participant's birth order (\%) } & Youngest & $94(25.13)$ & $39(20.86)$ & $55(29.41)$ & 2.37 \\
\hline & Intermediate & $131(35.03)$ & $67(35.83)$ & $64(34.22)$ & 0.05 \\
\hline & Oldest & 149 (39.84) & $81(43.32)$ & $68(36.36)$ & 1.12 \\
\hline \multirow{3}{*}{$\begin{array}{l}\text { Target brother or sister's } \\
\text { birth order (\%) }\end{array}$} & Youngest & 77 (20.59) & $21(11.23)$ & $56(29.9)$ & $18.91^{* * *}$ \\
\hline & Intermediate & $168(44.92)$ & $101(54.01)$ & $67(35.83)$ & $11.77^{* * *}$ \\
\hline & Oldest & $129(34.49)$ & $65(34.76)$ & $64(34.22)$ & 0 \\
\hline Living with sibling (\%) & Same & $19(4.95)$ & $7(3.74)$ & $12(6.42)$ & 0.89 \\
\hline
\end{tabular}

Note: *** $p \leq 0.001,{ }^{* *} p \leq 0.01,{ }^{*} p \leq 0.05$

As anxiety and depression are very strongly correlated $(r=0.53)$, we summed the two scores to obtain the emotional distress indicator.

\section{Self-esteem}

Self-esteem was assessed with the French version of Rosenberg's Self-Esteem Scale (SES). Translated and validated by Vallieres and Vallerand [53], the SES (e.g., "I would like to have more respect for myself" or "Sometimes I feel really useless") includes 10 items evaluated on a Likert scale ranging from 1 (Strongly disagree) to 4 (Strongly agree). The psychometric qualities of the instrument are satisfactory $(\alpha=.70-.90)$.

\section{Data analysis strategy}

The data collected in the present study were analyzed using R [54]. Descriptive statistics of our 13 variables of

Table 2 Means, standard deviations, and skewness coefficients of variables of interest for the whole sample $(N=374)$, and correlations between these variables

\begin{tabular}{|c|c|c|c|c|c|c|c|c|c|c|c|c|c|}
\hline & 1 & 2 & 3 & 4 & 5 & 6 & 7 & 8 & 9 & 10 & 11 & 12 & 13 \\
\hline \multicolumn{14}{|l|}{ 1. Warmth } \\
\hline 2. W. Kno & 0.90 & & & & & & & & & & & & \\
\hline 3. W. Int & 0.94 & 0.77 & & & & & & & & & & & \\
\hline 4. W. Sup & 0.94 & 0.76 & 0.85 & & & & & & & & & & \\
\hline 5. Conflict & -.19 & -0.09 & -0.22 & -0.21 & & & & & & & & & \\
\hline 6. C. Ant & -.24 & -0.13 & -0.26 & -0.26 & 0.90 & & & & & & & & \\
\hline 7. C. Dom & -.12 & -0.07 & -0.15 & -0.10 & 0.83 & 0.62 & & & & & & & \\
\hline 8. C. Qua & -0.14 & -0.05 & -0.16 & -0.17 & 0.90 & 0.77 & 0.59 & & & & & & \\
\hline 9. Rivalry & -0.31 & -0.25 & -0.29 & -0.30 & 0.37 & 0.32 & 0.31 & 0.35 & & & & & \\
\hline 10. R. Mat & -0.27 & -0.24 & -0.25 & -0.25 & 0.35 & 0.29 & 0.29 & 0.34 & 0.88 & & & & \\
\hline 11. R. Pat & -0.23 & -0.13 & -0.24 & -0.25 & 0.31 & 0.30 & 0.27 & 0.25 & 0.87 & 0.48 & & & \\
\hline 12. Distress & -0.04 & -0.03 & -0.03 & -0.06 & 0.16 & 0.14 & 0.13 & 0.14 & 0.18 & 0.16 & 0.12 & & \\
\hline 13. Esteem & 0.01 & 0.03 & 0.01 & -0.01 & -0.15 & -0.11 & -0.15 & -0.13 & -0.12 & -0.10 & -0.09 & -0.60 & \\
\hline Mean & 2.8 & 2.91 & 2.74 & 2.74 & 1.92 & 1.79 & 1.74 & 2.22 & 0.59 & 0.63 & 0.54 & 13.96 & 30.38 \\
\hline$S D$ & 0.91 & 0.87 & 0.98 & 1.07 & 0.72 & 0.74 & 0.83 & 0.88 & 0.52 & 0.57 & 0.59 & 5.96 & 6.47 \\
\hline Skewness & 0.23 & 0.07 & 0.25 & 0.25 & 0.85 & 0.80 & 1.23 & 0.69 & 0.67 & 0.67 & 0.97 & 0.66 & -0.40 \\
\hline
\end{tabular}




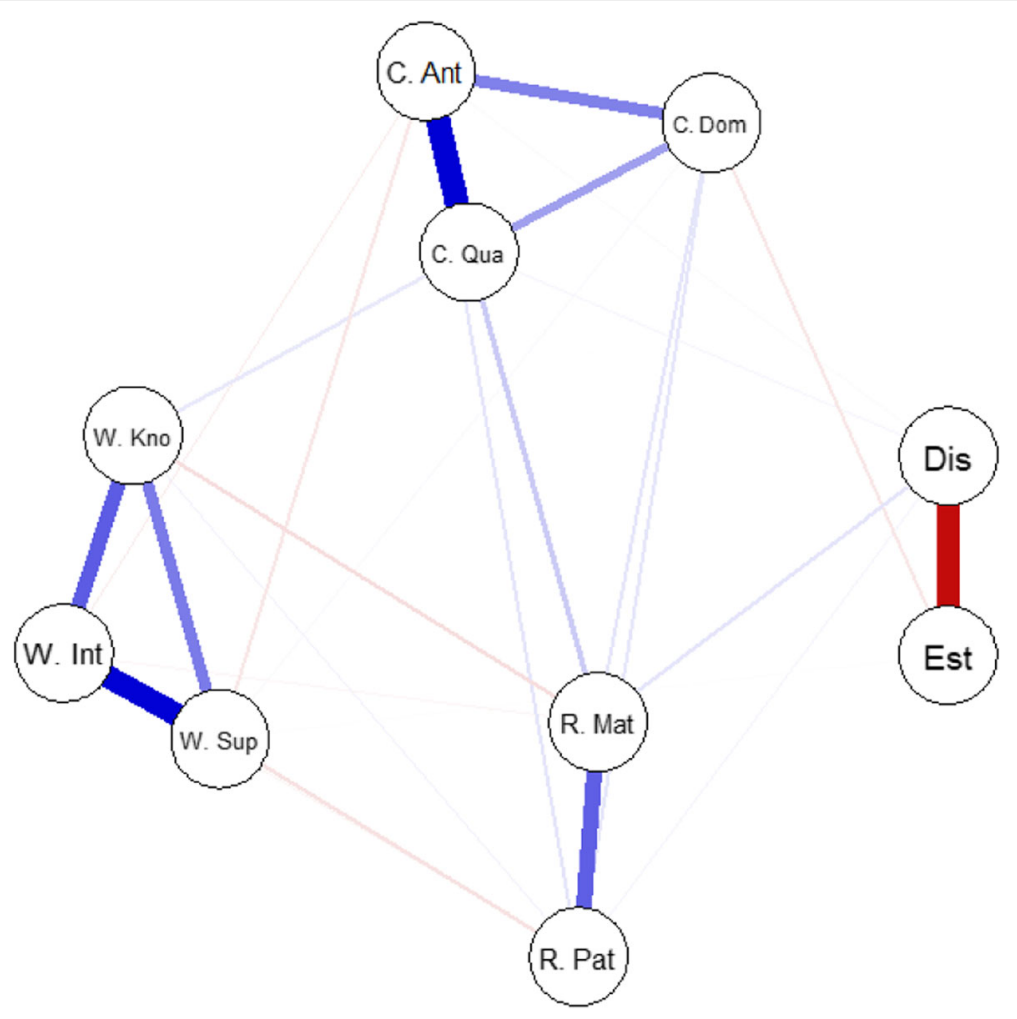

Fig. 1 Network of variables of interest. Note: W. Kno = knowledge; W. Int = intimacy; W. Sup = support; C. Ant = antagonism; C. Dom = dominance; C. Qua = quarreling; R. Mat = maternal rivalry; R. Pat = paternal rivalry. The estimated network was a sparse Gaussian graphical model. The distances between the variables in the figure reflect the strength of their correlations

interest obtained from the ASRQ-S, HAD scale and SES were computed with the two samples of siblings (Table 2). The correlations between these variables were also calculated. To facilitate the understanding of these correlations, they are displayed in both numerical (i.e., correlation matrix; see Table 2) and graphical (i.e., sparse Gaussian graphical model ${ }^{2}$; see Fig. 1) form. This model was computed using the qgraph $R$ package [55].

Next, we ran means comparisons between the two samples (siblings from the general population vs. siblings with a brother or sister with SZ). Paired Student $t$ tests were computed to determine whether the two samples had different means on our variables of interest (see Table 3). The subscales assessing maternal and paternal rivalry contained missing data, as participants had the option of not answering the rivalry items if one of their

\footnotetext{
${ }^{2}$ A sparse Gaussian graphical model represents a network made up solely of the most important partial correlations between the examined variables, to facilitate the interpretability of the resulting structure. In the psychological network literature, this sparsity is frequently achieved using the least absolute shrinkage and selection operator (LASSO) regularization parameter, while the minimization of the extended Bayesian information criterion is the tuning parameter used by the LASSO to control the degree to which regularization is applied [55].
}

parents had died. Whenever data were missing, we performed the analyses on the remaining data.

Finally, we performed mediation analyses to determine whether the quality of the sibling relationship mediated the putative effect of having a sibling with $\mathrm{SZ}$ on distress and self-esteem. We used the mediation $\mathrm{R}$ package [56] and followed the four steps recommended by Baron and Kenny [57].

\section{Results}

\section{Descriptive statistics}

Descriptive statistics for the variables of interest in the present study are set out in Table 2 and Fig. 1. At this descriptive level, three main results emerged.

First, correlations between the eight subscales of the ASRQ-S supported its construct validity. For instance, Table 2 shows that the weakest correlation between two subscales (i.e., Maternal Rivalry and Paternal Rivalry) supposed to belong to the same dimension was equal to 0.48 . This was still a strong correlation, and it was stronger than any correlation between two subscales supposed to belong to different dimensions. In the same vein, Fig. 1 shows that, as expected, the eight subscales of the ASRQ-S were organized into three separate clusters (i.e., warmth, conflict, and rivalry). 
Table 3 Means comparisons between siblings with a healthy brother or sister and siblings with a brother or sister experiencing schizophrenia on the quality of their sibling relationships, distress, and self-esteem

\begin{tabular}{|c|c|c|c|c|c|c|c|}
\hline \multirow[b]{2}{*}{ Variables } & \multicolumn{2}{|c|}{ General population group $(n=187)$} & \multicolumn{5}{|c|}{ Clinical siblings $(n=187)$} \\
\hline & $\bar{M}$ & $S D$ & $M$ & SD & $t$ & $p$ & $d$ \\
\hline Warmth & 3.07 & 0.94 & 2.53 & 0.78 & -6.04 & $<0.001^{* * *}$ & -0.44 \\
\hline W. Know & 3.1 & 0.87 & 2.72 & 0.82 & -4.48 & $<0.001^{* * *}$ & -0.33 \\
\hline W. Int & 2.99 & 1.04 & 2.5 & 0.87 & -4.99 & $<0.001^{* * *}$ & -0.36 \\
\hline W. Sup & 3.11 & 1.1 & 2.38 & 0.89 & -7.03 & $<0.001^{* * *}$ & -0.51 \\
\hline Conflict & 1.84 & 0.66 & 1.99 & 0.76 & 2.11 & $0.04^{*}$ & 0.15 \\
\hline C. Ant & 1.7 & 0.72 & 1.88 & 0.76 & 2.48 & $0.01^{* *}$ & 0.18 \\
\hline C. Dom & 0.43 & 0.43 & 0.48 & 0.43 & 1.02 & 0.31 & 0.07 \\
\hline C. Qua & 2.12 & 0.76 & 2.32 & 0.97 & 2.25 & $0.03^{*}$ & 0.16 \\
\hline Rivalry & 0.46 & 0.45 & 0.73 & 0.55 & 4.99 & $<0.001^{* * *}$ & 0.44 \\
\hline R. Mat & 0.5 & 0.51 & 0.75 & 0.59 & 3.7 & $<0.001^{* * *}$ & 0.33 \\
\hline R. Pat & 0.38 & 0.49 & 0.7 & 0.64 & 4.74 & $<0.001^{* * *}$ & 0.33 \\
\hline Distress & 13.21 & 5.36 & 14.71 & 6.42 & 2.42 & $0.02^{*}$ & 0.18 \\
\hline Esteem & 30.22 & 6.31 & 30.54 & 6.63 & 0.47 & 0.64 & 0.03 \\
\hline
\end{tabular}

Note. Ctrl Siblings with a healthy brother or sister, SZ Siblings with a brother or sister experiencing schizophrenia, M Mean, SD Standard deviation, W. Know Knowledge, W. Int Intimacy, W. Sup Support, C. Ant Antagonism, C. Dom Dominance, C. Qua Quarreling, R. Mat Maternal rivalry, R. Pat Paternal rivalry *** $p \leq 0.001$. ** $p \leq 0.01$. * $p \leq 0.05$

Second, conflict and rivalry appeared to be more closely correlated with emotional distress and selfesteem than warmth was. Thus, the three dimensions of sibling relationship quality were differently associated with wellbeing indicators.

Third, one variable (i.e., dominance) was positively skewed. The log-transformed version of this variable was therefore used in the analyses reported in the present study, including the correlations displayed in Table 2 and Fig. 1.

\section{Means comparisons}

We tested the hypotheses that, compared with siblings who have healthy brothers and sisters, siblings who have a brother or sister with SZ display less warmth and more conflict and rivalry in their sibling relationships. They are also more distressed and have lower self-esteem.

Our two hypotheses were generally confirmed. Compared with controls, siblings who had a brother or sister with SZ rated their sibling relationships more poorly, and reported more emotional distress (see Table 3). We failed to find a statistically significant difference between the two groups on only two variables: dominance, $t_{(186)}=1.02, p=0.31, d=$ 0.07 , and self-esteem, $t_{(186)}=0.47, p=0.64, d=0.03$.

\section{Mediation analyses}

To establish the presence of mediating effects, we followed the four steps recommended by Baron and Kenny [57]. Results are shown in Table 4.

First, the predictor variable (e.g., having or not having a sibling with SZ) has to be significantly related to the outcome variable (e.g., emotional distress or self-esteem). Here, the predictor variable predicted emotional distress $(\beta=0.25, p<0.05)$, but not self-esteem $(\beta=0.05, p>0.05)$. Thus, self-esteem was not examined further.

Second, the predictor variable has to be related to the mediator variables (e.g., ASRQ-S indicators). This criterion was met for every ASRQ-S variable except for dominance and overall conflict $(\beta=0.10, p>0.05$ and $\beta=0.20$, $p=0.05$ ), explaining why neither of these variables was analyzed further.

Table 4 Mediation analyses for the five sequences of variables meeting Baron and Kenny's (1986) criteria for the presence of mediation effects

\begin{tabular}{|c|c|c|c|c|c|c|}
\hline Predictor & Outcome & Mediator & $n$ & Total effect & Mediated effect & $p$ \\
\hline Sz vs. Ctrl & Distress & Antagonism & 374 & 0.25 & $0.03(11 \%)$ & 0.032 \\
\hline Sz vs. Ctrl & Distress & Quarrel & 374 & 0.25 & $0.03(10 \%)$ & 0.049 \\
\hline Sz vs. Ctrl & Distress & Rivalry & 374 & 0.21 & $0.09(39 \%)$ & 0.002 \\
\hline Sz vs. Ctrl & Distress & Maternal rivalry & 363 & 0.21 & $0.06(33 \%)$ & 0.010 \\
\hline Sz vs. Ctrl & Distress & Paternal rivalry & 363 & 0.21 & $0.05(22 \%)$ & 0.108 \\
\hline
\end{tabular}


Third, a mediation effect requires the mediator variable to be related to the outcome variable (e.g., emotional destress). As this condition was not met by the warmth dimension and three warmth subscales of the ASRQ-S ( $\beta \mathrm{s}$ ranging from -0.06 to $-0.03, p>0.05)$, they were removed. By contrast, antagonism $(\beta=0.13, p<0.01)$, quarreling $(\beta=$ $0.14, p<0.01)$, overall rivalry $(\beta=0.18, p<0.001)$, maternal rivalry $(\beta=0.16, p<0.01)$, and paternal rivalry $(\beta=0.12, p<$ $0.05)$ were all significantly related to emotional distress.

Finally, the initial effect of the predictor variable on the outcome variable must diminish when the mediator is entered as a second simultaneous predictor. Here, the effect of group (sibling with or without SZ) on emotional distress $(\beta=0.25, p<0.05)$ fell to $\beta=0.22 \quad(p<0.05)$ when either antagonism or quarreling was entered in the regression analysis. These two mediation effects of $\beta=$ 0.03 (11\% mediation for antagonism and 10\% for quarreling) were both statistically significant $(p<0.05)$.

The diminution of the effect of having a brother or sister with SZ on emotional distress was initially $\beta=0.21$, if we removed missing data on rivalry-related variables. The effect of having a sibling with SZ fell to $\beta=0.12$ (ns) when overall rivalry was included as a predictor of distress, and to $\beta=0.14$, ns (or $\beta=0.17, n s$ ) when maternal (or paternal) rivalry was included as a second predictor.

\section{Discussion}

Ours was the first study to highlight differences in sibling relationships depending on whether a brother or sister had been diagnosed with SZ. These differences took the form of more negative experiences of sibling relations in the SZ group. In addition, the siblings of individuals with SZ experienced more emotional distress than the siblings drawn from the general population. Interestingly, our findings showed that this emotional distress was partly explained by antagonism, quarreling and rivalry in the relationship with the ill sibling.

\section{Warmth in sibling relationships}

The siblings in our study who had a brother or sister with SZ felt less warmth in their sibling relationships than those who were drawn from the general population. Grieving for the relationship they used to enjoy with their sibling before he or she was diagnosed with SZ undoubtedly contributed to this feeling, as did the effort required to accept and adapt to this new brother or sister [58].

The siblings of individuals with SZ may sometimes experience fear. This fear is multifaceted, as it concerns not only their own mental health, but that of other family members, as well as the way other people view them and, of course, the suffering of their sibling $[3,4]$. Bowman's results suggested that a history of physical violence by brothers/sisters who have experienced an FEP significantly accounts for reduced warmth in sibling relationships [1]. Accordingly, our finding of a diminished feeling of warmth may be linked to a previous violent experience or assault.

In the present study, analysis of the ratings on the various ASRQ-S subscales revealed that the greatest intergroup difference concerned emotional support. According to Stålberg et al., healthy siblings find it hard to understand and anticipate the thoughts of their ill brother or sister [8]. This has a negative impact on communication and companionship within the dyad, and thus on the siblings' willingness to be supportive. Some do nonetheless make several attempts to provide support, but often become worn down by successive relapses, and eventually give up [59].

\section{Conflict in sibling relationships}

Our results also showed that the participants in the SZ sample reported more conflict in their sibling relationships than the participants drawn from the general population. The emotional burden, characterized by feelings of fear and impotence on the part of family members, can manifest itself as hostile and critical comments [60]. This hostility from close family and friends, reported in the literature in terms of expressed emotion [61, 62], substantially increases patients' risk of relapse [63], and perhaps their suicidality. The effect is twofold, as quarrels within the relationship impact not only the ill brother or sister but also the healthy siblings, whose emotional distress increases, as the results of the present study interestingly suggest.

Moreover, ratings on the Antagonism subscale revealed that participants in the SZ sample expressed a greater need to differentiate themselves from their ill brother or sister, even though we observed that this search for differentiation formed part of their emotional distress. Fear of courtesy stigma [64] has been shown to heighten the desire of siblings to set themselves apart from a brother or sister living with a mental disorder.

As already mentioned, Dominance was the only ASRQ-S subscale on which the two groups did not differ. Having a sister or brother with a disability does not favor the emergence of any form of dominance. It is hard for healthy siblings to view a brother or sister with a disability as an equal with whom they could have a relationship of dominance without betraying family loyalty, which requires them to be protective [65].

\section{Rivalry in sibling relationships}

Parents' commitment to their mentally ill offspring can be a source of concern for their other children, who fear for their mental and physical wellbeing [4]. For these siblings, their most important role is to watch over and take care of their parents $[3,4]$. This situation can make them feel lonely [3] and, in all probability, frustrated. The shifting positions and roles of the various family members generate comparisons and even criticisms among the healthy siblings, who start to resent their 
mentally ill brother or sister for monopolizing their parents' attention and energy [3, 4]. Taken together, these different aspects can explain why we observed such an effect of rivalry on siblings' emotional distress in the present study. Although authors have reported the opposite results for the siblings of children with developmental disorders, who actually express less rivalry than controls $[66,67]$, this may be because these young siblings feel guilty about competing with a brother or sister who has this type of disorder. So although they probably still feel rivalry, they express it less often [68]. Our results suggest that adults may feel more comfortable about expressing and admitting to this rivalry. Moreover, the later onset of SZ means that nonclinical siblings are suddenly forced to reassess their relationship with their mentally ill brother/sister. This late reassessment, coupled with a lack of understanding, may well generate a strong need for attention and support from their parents, such that the latter's reduced accessibility actually heightens rivalry within the sibling relationship.

\section{Limitations and future research directions}

The present study contributes to the literature on sibling relationships in adulthood and the specific features of these relationships in SZ. Indeed, our study was the first to compare siblings' relationships with a brother or sister experiencing SZ with a matched group of siblings drawn from the general population. Nevertheless, it had several limitations.

First, our results cannot be generalized, as our sample did not have a balanced sex ratio and all the participants were French. It is not surprising that our sample was mainly made up of women, given that we collected our data via social media [69]. Moreover, female overrepresentation has been a recurring feature of research on adult sibships $[16$, 70]. It is unlikely that having a more balanced sex ratio would have changed our results, as Bowman et al. found no effect of sex on any of the three dimensions of sibling relationships (measured using the validated long version of the ASRQ) [1]. Our recruitment procedure may have introduced another sample bias. Participants were recruited either via social media (support groups for the relatives of individuals with mental disorders) or via the UNAFAM family organization. The advantage of this procedure is that it was not hospital-based, and therefore allowed brothers and sisters who had no links to psychiatric institutions to share some of their experiences as siblings. However, it meant that participants either had to be members of a charity or else had to belong to an online support group for family members, meaning that they did not represent all the brothers and sisters of individuals with SZ. In addition to these two criteria, despite its speed, autonomy and easy access, the use of the online procedure did require computer skills and a reasonable Internet connection, which may have put off some potential participants.
Second, there were biases in the way we matched the two groups. Whereas participants who had a brother or sister with SZ had to think about their relationship with him or her when filling in the questionnaire, unselected siblings could think about any brother or sister they chose. Although our participants were matched on more variables than in previous studies comparing groups on sibling relationships [42, 71, 72], we did not control for either age differences between the dyads, birth order, or the number of persons in each sibship, which are liable to influence dimensions of sibling relationships [50].

Finally, in the present study, we chose to investigate the sibling relationship on the three main dimensions that are classically studied in adult sibships: warmth, conflict, and rivalry. However, other aspects of the sibling relationship deserve to be explored in future studies. For instance, methodologies based on actor-partner interdependence models could be used to shed light on the reciprocal mechanisms involved in sibling relationships. In addition, it might be useful to compare the experiences of siblings who all have a brother or sister with SZ. Future research could also compare relationships involving a sibling with SZ and relationships involving a sibling with a different mental disability.

\section{Conclusion}

To conclude, the quality of sibling relationships is a key area of research, owing to its impact on the continuing wellbeing and development of individuals throughout their lives [21]. The implementation of therapies that focus on strengthening the sibling relationships of individuals with SZ could help to protection their healthy siblings from emotional distress (e.g., depression and anxiety).

In order to strengthen relationships with siblings diagnosed with SZ, we first need to identify the variables that have the greatest influence on the quality of these relationships. In further studies, we therefore plan to identify the determinants of sibling relationships, both among sets of siblings drawn from the general population and among the siblings of individuals with SZ.

\section{Supplementary information}

Supplementary information accompanies this paper at https://doi.org/10. 1186/s12888-020-02510-6.

Additional file 1. Instructions and Basic Information.

\section{Abbreviations}

ASRQ: Adult Sibling Relationship Questionnaire; ASRQ-S: Adult Sibling Relationship Questionnaire-Short Form; FEP: First episode of psychosis; HAD scale: Hospital Anxiety and Depression scale; M: Mean; SD: Standard deviation; SES: Rosenberg's Self-Esteem Scale; SZ: Schizophrenia; UNAFAM: Union Nationale de Familles ou Amis de Personnes Malades et/ou Handicapées Psychiques (National Union of Families or Friends of Persons with Mental Disorders and/or Disabilities) 


\section{Acknowledgements}

Not applicable.

\section{Authors' contributions}

LP and HW designed the study and were a major contributor in writing the manuscript. LP acquired the data and wrote the first draft of the manuscript. JBP analyzed the data and interpreted its with LP. EB supervised the research and the writing of the manuscript. All authors read amended and approved the final manuscript

\section{Funding}

Not applicable.

\section{Availability of data and materials}

The datasets used and/or analyzed during the current study are available from the corresponding author on reasonable request.

\section{Ethics approval and consent to participate}

The research protocol was approved by Lille University's ethics committee for human-based research (2018-276-S61) and complied with the principles of the Declaration of Helsinki. Moreover, the participant's consents were obtained written.

\section{Consent for publication}

Not applicable.

\section{Competing interests}

The authors declare that they have no competing interests.

\section{Author details}

'LPCPP, Aix Marseille University, Aix-en-Provence, France. ${ }^{2}$ PsyCLE, Aix Marseille University, Aix-en-Provence, France.

Received: 30 August 2019 Accepted: 24 February 2020

Published online: 13 March 2020

\section{References}

1. Bowman S, Alvarez-Jimenez M, Howie L, McGorry P, Wade D. The impact of first-episode psychosis on the sibling relationship. Psychiatry. 2015;78(2): 141-55. https://doi.org/10.1080/00332747.2015.1051444.

2. Bowman S, Alvarez-Jimenez M, Wade D, Howie L, McGorry P. The impact of first episode psychosis on sibling quality of life. Soc Psychiatry Psychiatr Epidemiol. 2014;49(7):1071-81. https://doi.org/10.1007/s00127-013-0817-5.

3. Sin J, Moone N, Harris P, Scully E, Wellman N. Understanding the experiences and service needs of siblings of individuals with first-episode psychosis: a phenomenological study. Early Interv Psychiatry. 2012;6(1):53-9. https://doi.org/10.1111/j.1751-7893.2011.00300.x.

4. Sin J, Moone N, Harris P. Siblings of individuals with first-episode psychosis. J Psychosoc Nurs Ment Health Serv. 2008;46(6):33-40. https://doi.org/10. 3928/02793695-20080601-11.

5. Davtian H, Collombet É. Aidant familial en psychiatrie, une place " naturelle " ? Empan. 2014;94(2):47-52. https://doi.org/10.3917/empa.094.0047.

6. Friedrich RM, Lively S, Rubenstein L. Siblings' coping strategies and mental health services: a national study of siblings of persons with schizophrenia. Psychiatr Serv. 2008:59(3):261-7. https://doi.org/10.1176/appi.ps.59.3.261.

7. Gerace LM, Camilleri D, Ayres L. Sibling perspectives on schizophrenia and the family. Schizophr Bull. 1993;19(3):637-47. https://doi.org/10.1093/schbul/19.3.

8. Stålberg G, Ekerwald H, Hultman CM. At issue: siblings of patients with schizophrenia: sibling bond, coping patterns, and fear of possible schizophrenia heredity. Schizophr Bull. 2004;30(2):445-58. https://doi.org/10. 1093/oxfordjournals.schbul.a007091.

9. Hatfield AB, Lefley HP. Future involvement of siblings in the lives of persons with mental illness. Community Ment Health J. 2005;41(3):327-38. https:// doi.org/10.1007/s10597-005-5005-y.

10. Horwitz AV. Siblings as caregivers for the seriously mentally ill. Milbank Q. 1993;71(2):323-39. https://doi.org/10.2307/3350402.

11. Horwitz AV. Predictors of adult sibling social support for the seriously mentally ill an exploratory study. J Fam Issues. 1994;15(2):272-89. https://doi. org/10.1177/0192513X94015002007.

12. Lohrer SP, Lukens EP, Thorning H. Economic expenditures associated with instrumental caregiving roles of adult siblings of persons with severe mental illness. Community Ment Health J. 2006;43(2):129-51. https://doi.org/ 10.1007/s10597-005-9026-3.

13. Schmid R, Schielein $T$, Binder $H$, Hajak G, Spiessl $H$. The forgotten caregivers: siblings of schizophrenic patients. Int J Psychiatry Clin Pract. 2009:13(4):32637. https://doi.org/10.3109/13651500903141400.

14. Smith MJ, Greenberg JS, Mailick Seltzer M. Siblings of adults with schizophrenia: expectations about future caregiving roles. Am J Orthop. 2007;77(1):29-37. https://doi.org/10.1037/0002-9432.77.1.29.

15. Milevsky A, Smoot K, Leh M, Ruppe A. Familial and contextual variables and the nature of sibling relationships in emerging adulthood. Marriage Fam Rev. 2005;37(4):123-41. https://doi.org/10.1300/J002v37n04_07.

16. Stocker CM, Lanthier RP, Furman W. Sibling relationships in early adulthood. J Fam Psychol. 1997;11(2):210. https://doi.org/10.1037/0893-3200.11.

17. Brody GH. Sibling relationship quality: its causes and consequences. Annu Rev Psychol. 1998:49(1):1-24. https://doi.org/10.1146/annurev.psych.49.1.1.

18. Noller P. Sibling relationships in adolescence: learning and growing together. Pers Relat. 2005;12(1):1-22. https://doi.org/10.1111/j.1350-4126. 2005.00099.x.

19. Howe N, Petrakos H, Rinaldi CM, LeFebvre R. "This is a bad dog, you know... ": constructing shared meanings during sibling pretend play. Child Dev. 2005;76(4):783-94. https://doi.org/10.1111/j.1467-8624.2005.00877.x.

20. Youngblade LM. Individual differences in young children's pretend play with mother and sibling: links to relationships and understanding of other people's feelings and beliefs. Child Dev. 1995;66(5):1472-92. https://doi.org/ 10.1111/1467-8624.ep9510075274.

21. Cicirelli VG. Sibling relationships across the life span. US: Springer; 1995.

22. Howe N, Aquan-Assee J, Bukowski WM, Lehoux PM, Rinaldi CM. Siblings as confidants: emotional understanding, relationship warmth, and sibling selfdisclosure. Soc Dev. 2001;10(4):439-54. https://doi.org/10.1111/1467-9507.00174.

23. Buist KL, Deković M, Prinzie P. Sibling relationship quality and psychopathology of children and adolescents: a meta-analysis. Clin Psychol Rev. 2013;33(1):97-106. https://doi.org/10.1016/j.cpr.2012.10.007.

24. Gass K, Jenkins J, Dunn J. Are sibling relationships protective? A longitudinal study. J Child Psychol Psychiatry. 2007:48(2):167-75. https://doi.org/10.1111/ j.1469-7610.2006.01699.x.

25. Noller P, Feeney JA. Close Relationships: Functions, Forms and Processes. 1 re éd. New York: Psychology Press; 2013.

26. Riggio HR. Measuring attitudes toward adult sibling relationships: the lifespan sibling relationship scale. J Soc Pers Relat. 2000;17(6):707-28. https://doi.org/10.1177/0265407500176001.

27. Ponzetti JJ, James CM. Loneliness and sibling relationships. J Soc Behav Pers. 1997;12(1):103-12.

28. Sherman AM, Lansford JE, Volling BL. Sibling relationships and best friendships in young adulthood: warmth, conflict, and well-being. Pers Relat. 2006;13(2):151-65. https://doi.org/10.1111/j.1475-6811.2006.00110.x.

29. Branje SJT, van Lieshout CFM, van Aken MAG, Haselager GJT. Perceived support in sibling relationships and adolescent adjustment. J Child Psychol Psychiatry. 2004;45(8):1385-96. https://doi.org/10.1111/j.1469-7610.2004. 00332.x.

30. Conger K, Little WM. Sibling relationships during the transition to adulthood: young adult siblings. Child Dev Perspect. 2010;4(2):87-94. https://doi.org/10.1111/j.1750-8606.2010.00123.x.

31. Jensen AC, Whiteman SD, Fingerman KL. " Can't live with or without them: " transitions and young adults' perceptions of sibling relationships. J Fam Psychol. 2018;32(3):385-95. https://doi.org/10.1037/fam0000361.

32. Pulakos J. Brothers and sisters: nature and importance of the adult bond. Aust J Psychol. 1987;121(5):521-2. https://doi.org/10.1080/00223980.1987. 9915506.

33. Stewart RB, Kozak AL, Tingley LM, Goddard JM, Blake EM, Cassel WA. Adult sibling relationships: validation of a typology. Pers Relat. 2001;8(3):299-324. https://doi.org/10.1111/j.1475-6811.2001.tb00042.x.

34. White L. Sibling relationships over the life course: a panel analysis. J Marriage Fam. 2001;63(2):555. https://doi.org/10.1111/j.1741-3737.2001. 00555.x.

35. White LK, Riedmann A. Ties among adult siblings. Soc Forces. 1992;71(1):85102. https://doi.org/10.1093/sf/71.1.85.

36. Gold DT. Siblings in old age: something special. Can J Aging Rev Can Vieil. 1987:6(03):199-216. https://doi.org/10.1017/50714980800008424.

37. Lamb ME, Sutton-Smith B, Sutton-Smith B, Lamb ME. Sibling relationships: their nature and significance across the lifespan. Hillsdale: Psychology Press; 1982. 
38. von Benedek L. Frères et sœurs pour la vie : I'empreinte de la fratrie sur nos relations adultes. Paris: Eyrolles; 2013.

39. Meynckens-Fourez M, Tilmans-Ostyn É. Les ressources de la fratrie. Paris: Eres; 1999.

40. Burbidge J, Minnes P. Relationship quality in adult siblings with and without developmental disabilities: relationship quality in adult siblings. Fam Relat. 2014;63(1):148-62. https://doi.org/10.1111/fare.12047.

41. Tomeny TS, Ellis BM, Rankin JA, Barry TD. Sibling relationship quality and psychosocial outcomes among adult siblings of individuals with autism spectrum disorder and individuals with intellectual disability without autism. Res Dev Disabil. 2017;62:104-14. https://doi.org/10.1016/j.ridd.2017.01.008.

42. Orsmond Gl, Seltzer MM. Siblings of individuals with autism or Down syndrome: effects on adult lives. J Intellect Disabil Res. 2007;51(9):682-96. https://doi.org/10.1111/j.1365-2788.2007.00954.x.

43. Travis LL, Sigman M. Social deficits and interpersonal relationships in autism. Ment Retard Dev Disabil Res Rev. 1998;4(2):65-72. https://doi.org/10.1002/ (SICI) 1098-2779(1998)4:2\%3C65::AID-MRDD2\%3E3.0.

44. Yeargin-Allsopp M, Rice C, Karapurkar T, Doernberg N, Boyle C, Murphy C. Prevalence of autism in a US metropolitan area. JAMA. 2003;289(1):49-55. https://doi.org/10.1001/jama.289.1.49.

45. Greenberg JS, Seltzer MM, Orsmond Gl, Krauss MW. Siblings of adults with mental illness or mental retardation: current involvement and expectation of future caregiving. Psychiatr Serv. 1999;50(9):1214-9. https://doi.org/10. 1176/ps.50.9.1214.

46. Seltzer MM, Greenberg JS, Krauss MW, Gordon RM, Judge K. Siblings of adults with mental retardation or mental illness: effects on lifestyle and psychological well-being. Fam Relat. 1997;46(4):395-405. https://doi.org/10. 2307/585099.

47. Kate N, Grover S, Kulhara P, Nehra R. Relationship of quality of life with coping and burden in primary caregivers of patients with schizophrenia. Int J Soc Psychiatry. 2014;60(2):107-16. https://doi.org/10.1177/ 0020764012467598.

48. Janghorban R, Roudsari RL, Taghipour A. Skype interviewing: the new generation of online synchronous interview in qualitative research. Int J Qual Stud Health Well-Being. 2014;9(1):24152. https://doi.org/10.3402/qhw. v9.24152.

49. World Medical Association. World medical association declaration of Helsinki: ethical principles for medical research involving human subjects. JAMA. 2013;310(20):2191-4. https://doi.org/10.1001/jama.2013.281053.

50. Furman W, Buhrmester D. Children's perceptions of the qualities of sibling relationships. Child Dev. 1985;56(2):448-61. https://doi.org/10.2307/1129733.

51. Vallerand RJ. Toward a methodology for the transcultural validation of psychological questionnaires: implications for research in the French language. Can Psychol Can. 1989;30(4):662-80. https://doi.org/10.1037/ h0079856.

52. Lepine JP, Godchau M, Brun P. Anxiety and depression in inpatients. Lancet. 1985:326(8469):1425-6. https://doi.org/10.1016/S0140-6736(85)92589-9.

53. Vallieres EF, Vallerand RJ. Traduction et validation Canadienne-Française de l'échelle de l'estime de soi de Rosenberg. Int J Psychol. 1990;25(2):305-16. https://doi.org/10.1080/00207599008247865

54. CoreTeam R. R: a language and environment for statistical computing. Vienna: R Foundation for Statistical Computing; 2013. Retrieved from http:// www.R-project.org/.

55. Epskamp S, Borsboom D, Fried El. Estimating psychological networks and their accuracy: a tutorial paper. Behav Res Methods. 2018:50(1):195-212.

56. Tingley D, Yamamoto T, Hirose K, Keele L, Imai K. Mediation: R package for causal mediation analysis. J Stat Softw. 2014;59(5):1-38. https://doi.org/10. 18637/jss.v059.105.

57. Baron RM, Kenny DA. The moderator-mediator variable distinction in social psychological research: conceptual, strategic, and statistical considerations. J Pers Soc Psychol. 1986;51(6):1173. https://doi.org/10.1037/0022-3514.51.6.1173.

58. Riebschleger JL. Families of chronically mentally ill people: siblings speak to social workers. Health Soc Work. 1991;16(2):94-103. https://doi.org/10.1093/ hsw/16.2.94

59. Lukens EP, Thorning H, Lohrer S. Sibling perspectives on severe mental illness: reflections on self and family. Am J Orthop. 2004;74(4):489-501. https://doi.org/10.1037/0002-9432.74.4.489

60. Fitryasari R, Yusuf A, Nursalam TRD, Nihayati HE. Family members' perspective of family Resilience's risk factors in taking care of schizophrenia patients. Int J Nurs Sci. 2018;5(3):255-61. https://doi.org/10.1016/j.jjnss.2018. 06.002.
61. Barrowclough C, Parle M. Appraisal, psychological adjustment and expressed emotion in relatives of patients suffering from schizophrenia. $\mathrm{Br} \mathrm{J}$ Psychiatry. 1997;171(1):26-30. https://doi.org/10.1192/bjp.171.1.26.

62. Birchwood M, Cochrane R. Families coping with schizophrenia: coping styles, their origins and correlates. Psychol Med. 1990;20(4):857. https://doi. org/10.1017/S0033291700036552.

63. Butzlaff RL, Hooley JM. Expressed emotion and psychiatric relapse: a metaanalysis. Arch Gen Psychiatry. 1998;55(6):547-52. https://doi.org/10.1001/ archpsyc.55.6.547.

64. Goffman E. Stigma: notes on the management of spoiled identity. London: Penguin; 1963.

65. Griot M, Poussin M, Baltenneck N. Siblings' relationships and intellectual deficiency, questioning the way of parenting. Thérapie Fam. 2013;34(3):37186. https://doi.org/10.3917/tf.133.0371.

66. Doody MA, Hastings RP, O'Neill S, Grey IM. Sibling relationships in adults who have siblings with or without intellectual disabilities. Res Dev Disabil. 2010;31(1):224-31. https://doi.org/10.1016/j.ridd.2009.09.007.

67. Kaminsky L, Dewey D. Siblings relationships of children with autism. J Autism Dev Disord. 2001;31(4):399-410. https://doi.org/10.1007/s10826-0149915-6.

68. Wintgens A, Hayez J-Y. Le vécu de la fratrie d'un enfant souffrant de handicap mental ou de troubles autistiques : résilience, adaptation ou santé mentale compromise. Neuropsychiatr Enfance Adolesc. 2003;51(7):377-84. https://doi.org/10.1016/j.neurenf.2003.05.003

69. Perrin A. Social media usage. Pew Res Cent. 2015;7(4):52-68. https://doi.org/ 10.4236/cn.2015.74015

70. Walęcka-Matyja K. Psychometric properties of the polish adaptation of the adult sibling relationship questionnaire (ASRQ). Arch Psychiatry Psychother. 2014;16(4):77-88. https://doi.org/10.12740/APP/32460.

71. O'Neill LP, Murray LE. Anxiety and depression symptomatology in adult siblings of individuals with different developmental disability diagnoses. Res Dev Disabil. 2016;51-52:116-25. https://doi.org/10.1016/j.ridd.2015.12.017.

72. Rimmerman A. Involvement with and role perception toward and adult sibling with and without mental retardation. J Rehabil. 2001;67(2):10.

\section{Publisher's Note}

Springer Nature remains neutral with regard to jurisdictional claims in published maps and institutional affiliations.

Ready to submit your research? Choose BMC and benefit from

- fast, convenient online submission

- thorough peer review by experienced researchers in your field

- rapid publication on acceptance

- support for research data, including large and complex data types

- gold Open Access which fosters wider collaboration and increased citations

- maximum visibility for your research: over $100 \mathrm{M}$ website views per year

At $\mathrm{BMC}$, research is always in progress.

Learn more biomedcentral.com/submissions 